University of Nebraska - Lincoln

DigitalCommons@University of Nebraska - Lincoln

Bureau of Sociological Research - Faculty

Publications

Bureau of Sociological Research (BOSR)

May 2006

\title{
No Longer Intending: The Relationship Between Relinquished Fertility Intentions and Distress
}

Lynn K. White

University of Nebraska - Lincoln, Iwhite3@unl.edu

Julia McQuillan

University of Nebraska - Lincoln, jmcquillan2@Unl.edu

Follow this and additional works at: https://digitalcommons.unl.edu/bosrfacpub

Part of the Sociology Commons

White, Lynn K. and McQuillan, Julia, "No Longer Intending: The Relationship Between Relinquished Fertility Intentions and Distress" (2006). Bureau of Sociological Research - Faculty Publications. 11.

https://digitalcommons.unl.edu/bosrfacpub/11

This Article is brought to you for free and open access by the Bureau of Sociological Research (BOSR) at DigitalCommons@University of Nebraska - Lincoln. It has been accepted for inclusion in Bureau of Sociological Research - Faculty Publications by an authorized administrator of DigitalCommons@University of Nebraska - Lincoln. 


\title{
No Longer Intending: The Relationship Between Relinquished Fertility Intentions and Distress
}

\author{
Lynn White and Julia McQuillan \\ Department of Sociology, University of Nebraska-Lincoln, Lincoln, NE 68588-0324 \\ Correspondence:1white3@unl.edu
}

\begin{abstract}
We use data from both waves of the National Survey of Families and Households to assess whether relinquishing a serious intention to have (more) children leads to greater increases in depressive symptoms than continuing confidence in childbearing intentions. Our sample includes 2,200 individuals of childbearing age, men and women, all parities, and all marital statuses. Change score analysis shows that individuals who relinquished a serious intent to have children had elevated distress at Time 2 and that the association is conditioned by gender, health, and education. We find that fertility potential can be important to psychosocial well-being and that closing the door on future fertility, especially for women, those in ill health, and the better educated, leads to increased distress.
\end{abstract}

Keywords: change analysis, distress, fertility intentions, gender, infertility, parenthood.

For a generation or more, fertility levels in developed countries have been lower than expressed intentions (Hagewen \& Morgan, 2005). Although the gap between actual and intended children is smaller in the United States than in many other developed nations, a recent estimate suggests that $38 \%$ of American women will end their reproductive careers with fewer children than they intended as young women (Quesnel-Vallee \& Morgan, 2004). For most, this will mean having one or two children instead of two or three, but it also includes many who will never bear children. Perhaps $18 \%$ of American women entering childbearing age during the 1990s will not have children
(Abma, Chandra, Mosher, Peterson, \& Piccinino, 1997), but only $5 \%$ intended to be childless when they were young women (Quesnel-Vallee \& Morgan, 2004).

Previous research has examined how intentions are revised by life experiences (e.g., Heaton, Jacobson, \& Holland, 1999) and the correspondence of intentions and actual behavior (Hagewen \& Morgan, 2005; Quesnel-Vallee \& Morgan, 2004). The goal of this article is to move beyond change and persistence in intentions to examine the consequences for psychological distress when men and women relinquish their fertility intentions.

Using two waves of the National Survey of Families and Households (NSFH), we examine a two-stage process. First, we examine predictors of changing fertility intentions between waves. This analysis allows us to establish how changed intentions fit into a causal process and specifically to assess the possibility that more distressed individuals are quicker to give up fertility intentions than less distressed individuals. Having addressed these preliminary issues, we turn to our core issue: whether those who relinquish their fertility intentions have increased distress levels compared to those who sustain their intentions to have children.

\section{Prior work}

Theory

We rely on Pearlin's stress process model for understanding why no longer intending to have children might cause distress. Stress is hypothesized to result when people experience events or circum- 
stances with which they have insufficient resources to cope (Pearlin, Lieberman, Menaghan, \& Mullan, 1981). In addition to stressful life events, stressors also include nonevents and failures to achieve life goals (Aneshensel, 1992). When the threatened life goal is central to one's identity, distress is more likely to occur (Thoits, 1999). Because parenting is widely regarded as a core symbolic experience (Nock, 1987), we anticipate that relinquishing fertility intentions can be a chronic stressor.

This theoretical perspective suggests that, whether barriers to fertility are circumstantial or biomedical, relinquishing the intention of having future children will lead to increases in distress. Because individuals with at least one child have already attained a parental identity, we anticipate that canceling fertility intentions will pose less stress for those who are already parents than for nonparents. Although survey data suggest that men and women have similar childbearing expectations, intentions, and ideals (Thornton \& YoungDeMarco, 2001), qualitative data raise the possibility that the "motherhood mandate" (Hays, 1996; McMahon, 1995) is stronger than the "fatherhood mandate." Thus, we examine whether the consequences of relinquished intentions are stronger for women than men.

Like ours, most theoretical work using the stress process model focuses on predicting distress as an outcome. Other work, however, has raised the question of causal order (Ross \& Sastry, 1999). Most relevant to this study, Thoits (1994) argues that individuals act to deflect or redress the effects of stress, for example, by reducing their childbearing intentions in response to stress. As a result, we examine the possibility that intentions respond to rather than cause distress.

\section{Related empirical work}

We review three bodies of work-work on intentions, consequences of fertility barriers, and consequences of distress - that are helpful in framing our study.

\section{Fertility intentions.}

For half a century, demographers have used survey questions about intentions to gauge future fertility of individuals and societies. Conceptually intermediate between ideal fertility and concrete fertility plans, intentions are conceptualized as general ex- pectations about the future (Miller, 2004). Not surprisingly then, the correspondence between intentions and actual behavior is weak at the individual level, and older and married women have clearer fertility intentions than younger or unmarried women (Morgan, 1982). Nevertheless, research finds a consistent relationship between strength of intention and odds of having a child (Schoen, Astone, Kim, Nathanson, \& Fields, 1999).

Miller and Pasta (1995) suggest three kinds of reasons for failing to enact fertility intentions: spouse's intentions, life course factors (primarily age, parity, and marital status), and infecundity. Because our research focuses on failure to enact intentions, we examine each of these in more detail.

Thomson's (1997) work bears directly on the issue of couple disagreements. In cases where spouses disagree, she finds relatively equal effect for wives' and husbands' intentions, with cases of disagreement more often resolved in favor of the spouse who did not intend (additional) children. In our analysis of couples, we take this question one step further and ask whether the consequences of relinquishing strong intentions for a child depend on the partner's intentions.

Life course factors are thought to operate primarily through strength, continuity, and urgency of intention (Miller \& Pasta, 1995). An implication of the life course perspective is that changes in trajectories, for example, divorce or health problems, are likely to change intentions (Beets, Liefbroer, \& Gierveld, 1999). Beyond life course markers, Morgan's (2003) concept of competition directs us to consider the life experiences that compete with childbearing. These include failure to marry or to stay married, economic challenges, work-family competition, changed preferences, demands of current children, and health problems that can cause intentions to be unfulfilled or simply to change.

Regarding the third factor, fecundity, studies suggest that $10 \%$ of American women face current problems with impaired fecundity (Abma et al., 1997), with a lifetime prevalence of over one third (McQuillan, Greil, White, \& Jacob, 2003). A substantial portion of these women are able to have children, some with medical intervention. The relationship between subfecundity and survey questions on intent is unclear. Many people realize they face a biomedical barrier only after they try to set their intent into motion. In some cases, obstacles may reinforce their determination to have a child (so they 
are recorded as still intending), but others may say they no longer intend (Bulcroft \& Teachman, 2004).

Work by Heaton et al. (1999) directly addresses the issue of predictors of changes in fertility intentions using the same two-wave data set used in this paper. Their analysis, although limited to individuals with no children who are either never married or in their first marriage at both waves, provides a useful baseline for understanding patterns of intention change. They report that older age is the strongest predictor of relinquished fertility intentions. Compared to those who actually had a child between waves, those who no longer intend are significantly less likely to have married between waves, but education, income, and most attitudinal measures had insignificant effects. Generally, predictors of intention change were similar for men and women.

Several studies consider predictors of fulfilling fertility intentions. In a classic piece, Westoff and Ryder (1977) found that White married women's fertility intentions were more likely to be realized if they were young, married for a short duration, had fewer children, and had a shorter birth interval. More recently, Quesnel-Vallee and Morgan (2004) used the 1979 National Longitudinal Survey of Youth to examine predictors of discrepancies between 1982 fertility expectations and 2000 fertility. In general, those who expected large families more often failed to meet their targets than those who expected small families, but they also report that women who were still in school or unmarried when they stated their initial intentions were those mostly likely to have fewer children than expected.

Consequences of fertility barriers.

Although we have identified no work that bears directly on the consequences of relinquished fertility intentions, three bodies of work address aspects of the problem: work on biomedical infertility, on childlessness, and on the end of women's fecundity.

Biomedical infertility. Qualitative studies of clinic populations seeking infertility services produce accounts of distress, anxiety, and grief (Greil, 1991), but quantitative studies with control groups find weaker associations between infertility and distress, with effects stronger for women than men (Andrews, Abbey, \& Halman, 1991). A recent study of Midwestern women suggests that the long-term effect of biomedical infertility on distress is limited to those who have no biological or adopted children (McQuillan et al., 2003). King (2003) found evidence of a strong association between subfecundity and anxiety symptoms and that the association did not dissipate when medical help seeking for infertility was included in the analysis.

Childlessness. Although half of those who relinquish intentions for a child in this study are already parents, research on the consequences of childlessness may shed some light on psychological outcomes. The relationship between childlessness and distress is addressed most often in the gerontology literature. Koropeckyj-Cox (1998) and Zhang and Hayward (2001) found little relationship between having no children per se and distress, but Connidis and McMullin (1993) found that men and women who were childless because of circumstances showed higher levels of depression than those who were childfree by choice.

The end of fecundity. Women's fecundity generally ends earlier than men's, if not through hysterectomy or voluntary sterilization, then through menopause. A variety of mostly qualitative studies has considered the meaning of the end of fecundity for sexual identity and for the construction of femininity (e.g., Groat, Neal, \& Wicks, 1990, on voluntary sterilization; Hillis, Marchbanks, Tylor, \& Peterson, 1999, on menopause; Roeske, 1978, on hysterectomy). This work suggests that "closing the final door" (Elson, 2004) often is associated with feelings of regret and loss and may threaten women's sexual and gender identity.

Consequences of distress.

Surprisingly little empirical work considers the effects of distress on life trajectories. Wethington, Cooper, and Holmes (1997) hypothesized that depression would lead to psychological turning points. Using a definition of a turning point very similar to ours (In the past 12 months, did you give up for good on fulfilling one of your dreams?), they found no evidence that depression is associated with subsequent psychological turning points. Patterson, Coffey, Posterino, Carlin, and Bowes (2003), however, report that distress increased the risk of negative life events among adolescents and that negative events raised the risk of later distress. Thus, although support appears to be stronger for a path from negative life events to distress than vice versa, the issue remains open. 


\section{Statement of the problem}

Drawing from the stress process model, we test the hypothesis that individuals who relinquish their fertility intentions between waves experience increased distress compared to those who maintain their intentions. We use the NSFH two-wave panel, which provides measures of intentions and behaviors at two points in time approximately 6 years apart. Analyzing only those who are very sure or pretty sure they intend to have (more) children at Time 1, we examine the hypothesis that relinquishing fertility intentions is associated with increased distress.

Although we hypothesize distress as an outcome, two other causal arguments are plausible. A spurious model would posit that both fertility intentions and distress change in response to a common set of circumstances, for example, changes in income, employment, health, and marital status, and that no causal path exists between intentions and distress. The other possibility is that individuals who become distressed for some other reason (e.g., unemployment or divorce) relinquish their fertility goals as a result of their distress. To address both of these possibilities, we first examine predictors of changed intent using multinomial regression and then examine consequences of changed intent for distress using fixed effects pooled time series. Both analyses include life course factors of initial age, parity, and education, and changes in family income, employment, overall health, and marital status that have been demonstrated to predict both intentions (Heaton et al., 1999) and distress (Mirowsky \& Ross, 1992).

We also examine a series of moderating hypotheses. Because we anticipate that relinquishing fertility intentions will pose a more serious threat to the identity of women than men and to nonparents more than those who have at least one child, we examine whether effects of no longer intending are modified by gender and parity. We examine whether relinquished fertility intentions are more distressing in the face of fecundity indicators of age and health. Finally, we examine whether effects depend on socioeconomic status or marital status change.

Among the subset of married or cohabiting respondents who were in the same union in both waves and whose partner completed an interview at Time 1 (approximately one third of our full sample), we assess three additional questions: Do the effects of relinquishing fertility intentions on depressive symptoms depend on relationship quality and stability? Do the effects depend on partner's parity or on partner's fertility intentions at Time 1? Following Thomson (1997), we hypothesize that respondents who gave up their fertility ideals to match their partners' intentions will experience less distress than those whose partner also wanted children.

\section{Method}

\section{Data}

The analysis is based on the NSFH panel. In 19861987 , a random sample of 13,017 adults was identified through an area probability process. African Americans, Latinos, Puerto Ricans, the recently married, cohabitors, and those in stepfamilies were oversampled (Sweet, Bumpass, \& Call, 1988). The response rate was 74\%. In 1992-1994, reinterviews were completed with 10,008 or $76.9 \%$ of the original respondents (Sweet \& Bumpass, 1996). Both the original interview and the reinterview were done in person. Attrition between waves was significantly $(p<.05)$ but not substantially or linearly related to initial fertility intention: $19 \%$ of those who definitely did or definitely did not intend more children and $22 \%-25 \%$ of those who were uncertain left the study.

The sample used for this analysis starts with main respondents who were asked the fertility intentions questions at Time 1: women under 40, married men whose wives were under 40 , and single men who were under 40 . We included unmarried as well as married respondents, assuming that relinquishing fertility intentions may affect single as well as married individuals. Although effects of relinquishing fertility intentions are expected to be stronger for those with zero parity, we included all parities so that we could test this hypothesis. The subsample has an initial age range of 16-57 (18 men are older than 40 years) and includes all parities and marital statuses. The restriction to those with serious intentions to have (more) children means that the sample we use is relatively young (with a mean age 27 and an interquartile range of $22-29) ; 57 \%$ have no prior children and $40 \%$ are unmarried. 
NSFH included interviews with spouses/partners. Because $50 \%$ of our sample is not in union at Time 1 and only $71 \%$ of the partners of those in continuous unions were interviewed at Time 1, our initial analysis ignores the partner data. A supplemental analysis of respondents in unions includes data about partner intention and relationship quality and stability.

\section{Measures}

\section{Distress.}

Distress is measured by an average of 12 depressive symptom items taken from the Center for Epidemiologic Studies Depression Scale. Items ask about how many days in the last week respondents experienced symptoms such as restless sleep, inability to shake the blues, and trouble getting going. For both waves, the scale has an a reliability of .93, with a mean distress of 1.2. Both the original 20-item scale (Radloff, 1977) and shorter versions such as that used here have been widely used and extensively validated (Mirowsky \& Ross, 1992).

\section{Changed fertility intentions.}

NSFH asked respondents about actual and intended fertility at Time 1 and Time 2. Actual fertility at Time 1 is measured by, "How many children have you (given birth to/fathered)?" At Time 2, fertility between waves is assessed. Birth intentions at both waves are measured by the question, "Do you intend to have (a/another) child sometime?" Whether the answer was yes or no, a follow-up question asked whether they were very sure, moderately sure, or not at all sure about this intention.

Because the research question is about fertility intentions relinquished between waves, this analysis includes only those who expressed an affirmative intention to have a(nother) child and who said they were very sure or moderately sure about this $(n=2,287)$. Those who said they did not intend (more) children at Time 1 or who were uncertain about their fertility intentions are omitted. Using intentions at both waves and actual fertility in the interim, this subsample of serious intenders is divided into four groups: (a) did not have a child, but no longer intend to have a child at all; (b) did not have a child, but uncertain whether they will have a child; (c) did not have a child, but still confident they will have a child; and (d) had a child between waves. Postponing individuals (Group c) are treated as the omitted or comparison group. This group experienced no change in fertility or intentions between waves and so provides an appropriate and stable backdrop against which to evaluate change.

\section{Control variables.}

We include time-varying measures of family income, employment status, marital status, and health. Family income is measured by total family income, capped at the 99.5th percentile to reduce skew, and reported in $\$ 10,000$ units. The Time 2 family income measure is corrected for inflation between waves. Employment status is a dummy variable for each wave, coded 1 if the respondent works 35 hours or more each week and 0 if not. Marital status is a dummy variable coded 1 at each wave if the respondent is married and 0 if unmarried. In the change analyses, two variables, both coded 0 at Time 1 , are coded 1 at Time 2 if respondents changed from married at Time 1 to unmarried at Time 2 (marriage dissolves) or changed from unmarried at Time 1 to married at Time 2 (marry between waves). (The two dozen respondents who were in different marriages at Time 1 and Time 2 were coded as new marriages.) The omitted category for this analysis is those who did not change marital status. Health is measured by the question, "Compared with other people your age, how would you describe your health?" Responses ranged from $4=$ excellent to $0=v e r y$ poor .

Gender, education, age, and parity are included as time-invariant modifiers. Gender is coded $f e-$ male $=1$ and male $=0$. Because education changes little in adult populations, the potential modifying effect of education is examined using years of education at Time 1. Actual age rather than changed age between interviews is important for fertility outcomes, and thus we test whether the effects of relinquished fertility intentions depend upon age by using the Time 1 measure of age. Parity 0 is a dummy variable coded 1 for those who had borne no children at Time 1.

To control for the variability in time between interviews (range $=4-8$ years), we include a timevarying covariate for years between waves. This variable is coded 0 at Time 1 , with a mean score at Time 2 of 5.9 years. Because of missing data, primarily on income $(27 \%$ missing at Time 1$)$, the expectation maximization procedure in SPSS was used to impute data for all missing data (Hill, 
1997). Columns 1 and 2 in Table 1 provide descriptive data about the variables.

For the subsample of partnered individuals, relationship quality is the average of 2 items, a single-item indicator of relationship quality (Taking things all together, how would you describe your relationship? coded 0 =very unhappy to 6 =very happy) and a single-item indicator of relationship stability (During the past year, have you ever thought that your relationship might be in trouble?). To give both items the same metric, marital instability was coded yes $=0$ and $n o=6$. A dummy variable indicates cases where neither partner has children. Partners' intentions at Time 1 were recorded as a 6-point ordinal variable ranging from $1=$ very sure do not intend to $6=$ very sure intend.

\section{Analysis}

We first examine the predictors of changed intentions and then examine the consequences of changed intentions for distress. Because changed fertility intentions are measured by a typology that compares intentions at Time 1 and Time 2, we cannot combine both analyses in a single two-step model. Instead, we use multinomial regression to examine the predictors of changed intentions and fixed effects pooled time series to examine the consequences of changed intentions for distress.

Fixed effects pooled time series is a change score approach to modeling change. It is concerned with change within individuals over time: Change in the dependent variable is explained by change in the independent variables. Thus, we anticipate that changes in fertility intentions, marital status, health, and so on will predict change in distress. Because the analysis focuses only on change, timeinvariant characteristics that vary across but not within individuals, such as gender or initial parity, enter the analysis only as modifiers. For example, gender is not conceptualized as an independent cause of change in distress, but the effect of changing fertility intentions on changing distress might depend on gender. Because change score analyses control for prior levels of distress, they emulate classic pretest posttest experimental designs, replacing random assignment by adjusting for prior differences in distress between those who did and did not change their intention (Johnson, 2005). By focusing only on change, all individual character-

Table 1. Descriptive Data for Subsample of Individuals Who Intended to Have (More) Children at Time 1, Total and by Intentions Outcome Between Waves.

\begin{tabular}{|c|c|c|c|c|c|c|c|}
\hline & $M$ & $S D$ & $\begin{array}{l}\text { No Longer } \\
\text { Intend }\end{array}$ & $\begin{array}{l}\text { Now Unsure } \\
\text { Intend }\end{array}$ & $\begin{array}{l}\text { Still } \\
\text { Intend }\end{array}$ & $\begin{array}{l}\text { New } \\
\text { Baby }\end{array}$ & $F$ \\
\hline Distress Time 1 & 1.23 & 1.26 & $1.03 \mathrm{a}$ & $1.36_{\mathrm{b}}$ & $1.38_{\mathrm{b}}$ & $1.21_{\mathrm{ab}}$ & $5.70^{* *}$ \\
\hline Distress Time 2 & 1.17 & 1.21 & $1.17_{\mathrm{a}}^{\mathrm{a}}$ & $1.28_{\mathrm{a}}^{\circ}$ & $1.09^{\circ}$ & $1.19 a^{d o}$ & 1.10 \\
\hline Family income Time $1^{\mathrm{a}}$ & 3.00 & 2.16 & $3.07_{a}^{a}$ & $2.68_{\mathrm{ab}}^{\mathrm{a}}$ & $2.60_{\mathrm{b}}^{\mathrm{a}}$ & $3.16_{a}^{a}$ & $9.35^{* *}$ \\
\hline Family income Time $2^{\mathrm{a}}$ & 4.08 & 2.63 & $4.07_{\mathrm{a}}^{\mathrm{a}}$ & $4.18_{\mathrm{a}}^{\mathrm{a}}$ & $4.14_{\mathrm{a}}^{\circ}$ & $4.06_{a}^{a}$ & .17 \\
\hline Work full time Time 1 & .65 & .48 & $.71_{\mathrm{ab}}^{\mathrm{a}}$ & $.72_{\mathrm{b}}^{\mathrm{a}}$ & $.62_{a}^{a}$ & $.64_{\mathrm{ab}}^{\mathrm{a}}$ & $3.36^{*}$ \\
\hline Work full time Time 2 & .64 & .48 & .68 & .78 & $.76^{\circ}$ & $.56 \mathrm{~b}$ & $27.54^{* *}$ \\
\hline Health Time 1 & 3.23 & .71 & $3.20_{a}$ & $3.30_{a}$ & $3.24_{\mathrm{a}}^{\mathrm{a}}$ & $3.22 \mathrm{a}$ & .69 \\
\hline Health Time 2 & 3.08 & .75 & $2.96_{a}^{a}$ & $3.11_{\mathrm{ab}}^{\mathrm{a}}$ & $3.18_{\mathrm{b}}^{\mathrm{a}}$ & $3.08_{\mathrm{ab}}^{\mathrm{a}}$ & $5.74^{* *}$ \\
\hline Married Time 1 & .51 & .50 & $.45_{a}^{a}$ & $.36^{a v}$ & $.20_{b}$ & $.65_{c}$ & $121.82^{* *}$ \\
\hline Married Time 2 & .64 & .48 & $.51_{\mathrm{b}}^{\mathrm{a}}$ & $.42_{\mathrm{ab}}^{\mathrm{a}}$ & $.35_{\mathrm{a}}^{\mathrm{D}}$ & $.80_{\mathrm{c}}$ & $145.08^{* *}$ \\
\hline Age Time 1 & 26.52 & 5.52 & $29.66_{a}$ & $27.19_{b}$ & $24.41_{c}$ & $26.40_{b}$ & $77.94^{* *}$ \\
\hline Education Time 1 & 13.30 & 2.32 & $13.42^{a}$ & $13.18_{\mathrm{a}}$ & $13.30_{\mathrm{a}}$ & $13.29 \mathrm{a}$ & .44 \\
\hline Parity 0 at Time 1 & .57 & .50 & $.48_{a}^{a}$ & $.72_{b}$ & $.85_{c}{ }^{a}$ & $.48_{a}^{a}$ & $82.02^{* *}$ \\
\hline Female & .52 & .50 & $.54_{\mathrm{a}}^{\circ}$ & $.43_{b}$ & $.42_{\mathrm{b}}$ & $.56_{\mathrm{a}}^{\mathrm{a}}$ & $10.19^{* *}$ \\
\hline$N$ & 2,287 & & 346 & 134 & 483 & 1,324 & \\
\hline
\end{tabular}

Note: Income is coded in $\$ 10,000$ and adjusted for inflation between Times 1 and 2. Differences among intentions outcomes categories were tested using an analysis of variance $F$ test. Means in the same row that do not share subscripts differ at $p<$ .05 in the Tukey Honestly Significant Difference comparison.

a Income is reported in units of $\$ 10,000$.

${ }^{*} p<.05 .{ }^{* *} p<.01$. 
istics that remain stable over time and that might have influenced the initial level of distress are controlled (Allison, 1994).

\section{Results}

\section{Descriptive results}

The analysis focuses on those who initially seriously intend (more) children. At the first interview, this group of 2,287 respondents was relatively young, half were unmarried, and $57 \%$ had no children. Over half $(58 \%)$ had a new baby between waves, but $15 \%(n=346)$ no longer intended to have a child, $6 \%(n=134)$ became uncertain whether they would have (more) children, and $21 \%(n=483)$ continued to be confident about having children at the second interview.

The right side of Table 1 shows that this categorical measure of changes in fertility intention is significantly related to most of the predictor variables in the model at the bivariate level. At Time 1 , distress is significantly lower for those who no longer intend at Time 2 than for other categories of respondents who seriously intend to have a child at Time 1 . On the surface then, there is no support for the argument that distressed individuals are more likely to relinquish fertility intentions. The most significant differences among the intentions categories are for demographic and life course variables. Compared to those who remain confident that they will have more children, those who no longer intend are more likely to be women and to be married, older, and already parents at Time 1. Those who actually had a new baby are most likely to be married at Time 1 . The next step in the analysis is to shift our focus from cross-sectional and bivariate associations to assess change in a multivariate model.

\section{Predictors of changed intentions}

We use multinomial regression to consider the predictors of changed intentions. In addition to establishing the relationship between changed intentions and the predictor variables, we are especially interested in whether there is any evidence that changed intentions are a product of rather than a cause of distress. Model 1 in Table 2 presents the results when changed intentions between waves are regressed on Time 1 predictors. This analysis allows us to assess, for example, if level of distress at Time 1 predicts change in intentions at Time 2. Model 2 adds Time 2 measures of time-varying predictors, with the result that these Time 2 coefficients can be interpreted as the effect of change in the predictor on changed intentions.

Results (Table 2, Model 1) provide no support for the alternative causal order. Contrary to the hypothesis of a reversed causal order, individuals with higher distress at Time 1 are significantly less likely to relinquish their fertility intentions than are those who continue to intend additional children (the omitted group). Change in distress (Model 2) is not associated with relinquished or weakened fertility intentions.

Results of the other variables in this table support the expectation that changes in intentions are associated with life course measures. Model 1 shows that older individuals are more likely to relinquish a serious fertility intention than younger people, confirming the findings of Heaton et al. (1999) on a narrower subsample. Those with higher educations and zero parity are less likely to relinquish their intention, and those with full-time employment are more likely to relinquish their intention (Model 1). Perhaps, because aging is a stronger biological barrier to fertility for women, women are significantly more likely to relinquish a fertility intention over the average 6-year time span between waves than men. The key finding from the change analysis in Model 2 is that, although Time 1 health is not related to relinquishing fertility intentions, improved health is related to a significantly lower likelihood of relinquishing one's fertility intentions.

These findings confirm that health, age, parity, marital status, education, gender, and employment are related to changed fertility intentions, suggesting that it is important to control these factors when examining the consequences of changed intentions. Critically, however, this analysis provides no evidence that high or increasing distress is associated with relinquished fertility intentions. In fact, higher distress is associated significantly with continuing to intend.

\section{Consequences of changed intentions}

Change analysis using fixed effects pooled time series begins by regressing changes in distress on the measures of changed fertility intent and changes 
Table 2. Predictors of Changed Fertility Intentions Among Respondents Who Intend (More) Children at Time 1.

\begin{tabular}{|c|c|c|c|c|c|c|c|c|c|c|c|c|}
\hline & \multicolumn{6}{|c|}{ Model 1} & \multicolumn{6}{|c|}{ Model 2} \\
\hline & \multicolumn{2}{|c|}{$\begin{array}{l}\text { No Longer } \\
\text { Intend }\end{array}$} & \multicolumn{2}{|c|}{$\begin{array}{l}\text { Unsure } \\
\text { Now Intend }\end{array}$} & \multicolumn{2}{|c|}{ New Baby } & \multicolumn{2}{|c|}{$\begin{array}{l}\text { No Longer } \\
\text { Intend }\end{array}$} & \multicolumn{2}{|c|}{$\begin{array}{l}\text { Unsure } \\
\text { Now Intend }\end{array}$} & \multicolumn{2}{|c|}{ New Baby } \\
\hline & $B$ & $S E$ & B & $S E$ & B & $S E$ & $B$ & SE & $B$ & $S E$ & $B$ & $S E$ \\
\hline \multicolumn{13}{|l|}{ Variables } \\
\hline Distress Time 1 & $-.205^{* *}$ & .067 & .045 & .076 & -.029 & .047 & $-.244^{* *}$ & .071 & .002 & .080 & -.053 & .051 \\
\hline Distress Time 2 & & & & & & & .060 & .074 & .162 & .091 & $.137^{*}$ & .061 \\
\hline Income Time 1 & .019 & .044 & -.066 & .064 & .014 & .036 & .050 & .047 & -.062 & .066 & .058 & .039 \\
\hline Income Time 2 & & & & & & & -.050 & .036 & .012 & .047 & $-.078^{* *}$ & .029 \\
\hline Work full time Time 1 & $.428^{*}$ & .178 & .408 & .232 & $.278^{*}$ & .133 & .363 & .186 & .327 & .239 & $.328^{*}$ & .144 \\
\hline Work full time Time 2 & & & & & & & -.084 & .187 & .216 & .256 & $-.787^{* *}$ & 149 \\
\hline Health Time 1 & -.101 & .111 & .197 & .150 & -.027 & .088 & .035 & .117 & .249 & .156 & .012 & .096 \\
\hline Health Time 2 & & & & & & & $-.335^{* *}$ & .113 & -.102 & .148 & -.063 & .094 \\
\hline Married Time 1 & $.415^{*}$ & .189 & $.611^{*}$ & .243 & $1.631^{* *}$ & .146 & .360 & .205 & $.638^{*}$ & .259 & $1.009^{* *}$ & .158 \\
\hline Married Time 2 & & & & & & & .308 & .183 & .011 & .232 & $1.699 * *$ & .141 \\
\hline Age Time 1 & $.181^{* *}$ & .018 & $.121^{* *}$ & .022 & .029 & .015 & $.176^{* *}$ & .018 & $.121^{* *}$ & .022 & .016 & .016 \\
\hline Education Time 1 & $-.118^{\star *}$ & .037 & $-.130^{* *}$ & .049 & -.060 & .031 & $-.098^{*}$ & .040 & $-.132^{*}$ & .052 & -.040 & .035 \\
\hline Parity 0 Time 1 & $-1.141^{* *}$ & .191 & -.242 & .258 & $-1.251^{* *}$ & .158 & $-1.092^{* *}$ & .193 & -.196 & .260 & $-1.292^{* *}$ & .165 \\
\hline Female & $.664^{* *}$ & .164 & .167 & .211 & $.366^{* *}$ & .126 & $.602^{* *}$ & .169 & .158 & .215 & .100 & .137 \\
\hline Time & & & & & & & .094 & .085 & .061 & .109 & .116 & .070 \\
\hline Constant & -3.041 & & -3.515 & & 0.985 & & -3.054 & & -4.072 & & .395 & \\
\hline Nagelkirke $R^{2}$ & .291 & & & & & & .383 & & & & & \\
\hline
\end{tabular}

Note: Multinomial regression. Omitted category is respondents who did not have a child between waves but continued to express an intention to do so. $N=2,287$.

${ }^{*} p<.05 .{ }^{* *} p<.01$.

in family income, full-time employment, health, marital status, and time between waves. Invariant characteristics (gender and Time 1 education, age, and parity) are included in Model 2 as modifying variables.

The main effects analysis in Model 1 of Table 3 shows support for our hypothesis. The first row of Model 1 shows that individuals who no longer intend to have children have significantly more distress $(b=.294, p<.01)$ than those who continue to feel confident about their intention to have a child (the comparison group). Because the standard deviation for depressive symptoms is 1.2 , this coefficient represents an effect size of .24 . The effect of weakened intentions is about a third of that for no longer intending and is not significant. The effect of no longer intending is significant despite controlling for changes in measures that should independently affect distress and intentions.

Changes in depressive symptoms are not related to changes in our time-varying measure of socioeconomic status (family income), but they are related in expected ways to changes in employment, marital status, and health. As prior research on distress suggests (Mirowsky \& Ross, 1992), employment, marriage, and health are associated with decreased distress whereas divorce is associated with greater distress. Our results show that new parents experience an increase in depressive symptoms between waves, an outcome congruent with prior work linking parenthood to psychological distress (Umberson \& Gove, 1989). Because age is negatively associated with distress scores, it is not surprising that greater time elapsed between interviews is associated with greater decreases in distress.

The next step was to test whether the effect of changes in fertility intentions depended on changes in income, marital status, or health, or on time-invariant factors of gender and Time 1 age, parity, or education (mean centered). For each proposed interaction effect, a multiplicative term was created (e.g., No Longer Intend $\times$ Gender). When all eight interaction effects were added simultaneously to Model 1, the model improved significantly ( $F$ change $=2.88, d f=8 / 2,287$ ), and results showed that the effect of changed intentions was modified significantly by gender, education, and 
Table 3. Predictors of Change in Distress Among Respondents Who Intended More Children at Time 1.

\begin{tabular}{|c|c|c|c|c|}
\hline & \multicolumn{2}{|c|}{ Model 1} & \multicolumn{2}{|c|}{ Model 2} \\
\hline & $B$ & SE & $B$ & $S E$ \\
\hline No Longer Intend & $.294^{* *}$ & .101 & $-.166^{* *}$ & .525 \\
\hline$\times$ Female & & $.454^{* *}$ & .156 & \\
\hline × Health Change & & $-.312^{* *}$ & .102 & \\
\hline$\times$ Education Time 1 & & $.085^{*}$ & .033 & \\
\hline Weaken fertility intentions & .096 & .140 & .096 & .139 \\
\hline Intended and had new baby & $.169^{*}$ & .076 & $.169^{*}$ & .076 \\
\hline Time between waves & $-.033^{* *}$ & .012 & $-.033^{* *}$ & .012 \\
\hline Change in family income & -.001 & .012 & -.001 & .012 \\
\hline Change in full-time work & $-.137^{*}$ & .055 & $-.127^{*}$ & .055 \\
\hline Change in health & $-.198^{* *}$ & .036 & $-.175^{\star *}$ & .037 \\
\hline Marry between waves & $-.274^{\star *}$ & .074 & $-.269^{* *}$ & .074 \\
\hline Marriage dissolves between waves & $.434^{* *}$ & .119 & $.432^{* *}$ & .119 \\
\hline$R^{2}$ (within) & .038 & & .047 & \\
\hline Constant & 1.956 & & 1.878 & \\
\hline
\end{tabular}

Note: Fixed effects pooled time series, $n=2,287$ NSFH respondents. Omitted category is respondents who did not have a child between waves but continued to express the intent to do so.

${ }^{*} p<.05 .{ }^{* *} p<.01$.

changes in health. Model 2 of Table 3 presents the results when only these three interactions are included in the model.

In the presence of three interactions, the effect of no longer intending in Model 2 must now be read as the effect of relinquishing fertility intentions among men with ill health and average education. Among the group who no longer intend to have (more) children, women had a significantly and substantially greater increase in depressive symptoms than men $(p=.004)$. Among women, relinquishing a serious fertility intention was associated with a 0.45 greater increase in depressive symptoms than for men. This is equivalent to approximately one third of a standard deviation in distress levels. Despite decades of growing similarity in men's and women's adult roles, this finding suggests that the intent to have children is more important for women's than men's psychological well-being.

The increase in distress among those who no longer intend is significantly reduced for respondents in better health $(p=.002)$. Each decrement in health is associated with a significant and substantial reduction in the effect of relinquished fertility intentions on distress, with the result that the effect is nullified when health is very good or excellent. This suggests that relinquishing fertility intentions in conjunction with declining health is more distressing than relinquishing intentions for other reasons. The interaction effect for education is positive, meaning that relinquishing fertility intentions is associated with greater increases in distress for better educated respondents.

It is striking that the effects of relinquished fertility intentions are not significantly different for those without children than for those who already had biological children at Time 1 . We explored this finding by using a trichotomous coding (no, one, or two or more children), a different cutting point $(0,1$ compared to 2 or more children), and a two-way interaction of parity and gender. Results continued to be insignificant, suggesting that relinquishing future fertility prospects is distressing at all parities. We address this further in the discussion. The effect of relinquishing a serious intent to have (more) children was not significantly different for those who changed marital statuses compared to those who did not, and it did not depend on respondent's initial age or changes in family income.

Analysis of respondents in union.

Because we believe it is important to include unmarried individuals in a study of fertility intention, the analysis reported in Table 3 did not in- 
Table 4. Predictors of Change in Distress Among Married and Cohabiting Respondents Who Intended More Children at Time 1 .

\begin{tabular}{|c|c|c|c|c|c|c|}
\hline & \multicolumn{2}{|c|}{ Model 1} & \multicolumn{2}{|c|}{ Model 2} & \multicolumn{2}{|c|}{ Model 3} \\
\hline & $B$ & $S E$ & $B$ & $S E$ & $B$ & $S E$ \\
\hline $\begin{array}{l}\text { No Longer Intend } \\
\times \text { Relationship Quality }\end{array}$ & .187 & $\begin{array}{c}.179 \\
-.156^{* *}\end{array}$ & $\begin{array}{l}.114 \\
.057\end{array}$ & .178 & $.955^{* *}$ & .357 \\
\hline Weaken fertility intentions & -.254 & .255 & -.287 & .253 & -.281 & .252 \\
\hline Intended and had new baby & -.046 & .146 & -.118 & .145 & -.112 & .144 \\
\hline Time between waves & .002 & .024 & .007 & .024 & .007 & .023 \\
\hline Change in family income & .003 & .015 & .000 & .014 & .000 & .014 \\
\hline Change in full-time work & -.003 & .079 & .006 & .078 & -.006 & .078 \\
\hline Change in health & $-.119^{*}$ & .049 & -.091 & .049 & -.081 & .049 \\
\hline Change in relationship quality & & $-.093^{* *}$ & .019 & $-.081^{* *}$ & .019 & \\
\hline$R^{2}$ (within) & .011 & & .035 & & .042 & \\
\hline Constant & 1.330 & & 1.795 & & 1.699 & \\
\hline
\end{tabular}

Note: Fixed effects pooled time series, $n=992$ NSFH respondents who were in the same union at Time 1 and Time 2 , and whose partner participated in Wave 1. Omitted category is respondents who did not have a child between waves but continued to express the intent to do so.

${ }^{*} p<.05 .{ }^{* *} p<.01$.

clude information about partners or relationship quality. We now turn to a subsample of 992 individuals who were in the same union (marriage or cohabitation) at Time 1 and Time 2 and whose partners answered the questions about childbearing intentions at Time 1 . This is obviously a selective subset of married respondents. To the extent that disagreements over fertility intentions are associated with partner noncooperation or marital dissolution, we will miss those individuals who are likely to be most distressed. Thus, we regard this as a conservative test of the hypotheses.

Using this subsample, we ask whether effects of relinquishing a fertility intention are modified by relationship quality or partner's intentions and parity. The analysis is similar to that for the larger group except that the two variables noting changed marital status are dropped. Model 1 of Table 4 is analogous to Model 1 for the larger group. It reports the main effects of relinquished fertility intentions on the subsample with responding partners, controlling for time-varying background variables. In part because of the lower power of the smaller sample, the main effect of dropping fertility intentions is not significant in this sample of people in stable unions. In Model 2, changed relationship quality is added to the model. As we might expect, those whose relationships deteriorated have significantly greater increase in depressive symptoms.
We examined three modifying variables unique to respondents in union: partner's fertility intention and parity at Time 1 and changes in relationship quality. The terms for partner's fertility intention and parity were not significant, but the effect of relinquished fertility is modified significantly by relationship quality ( $p=.007)$. When relationship quality is 0 (relationship quality is rated very poor and respondent thinks the relationship is in trouble), relinquishing a serious intent to have a child is associated with a 0.955 increment in depressive symptoms; this effect is reduced by -.16 for every increment in relationship quality. Thus, a person who had the highest score on relationship quality (6) would experience virtually no change in depressive symptoms. This finding supports a common sense notion that relinquished fertility intentions are less distressing in a strong relationship. The gender, health, and education interactions found in the main analysis did not reach significance in this subsample.

\section{Summary and Discussion}

Using two waves of data from NSFH, we examined the hypothesis that individuals who relinquish their intentions to have (more) children report more increases in depressive symptoms than those who continue to feel confident about their childbearing intentions. Analysis was restricted to 
those who had definite intentions to have a child at Time 1.

First, we used multinomial regression to examine the predictors of changed fertility intentions, with special attention to the possibility that distress was the cause rather than the consequence of weakened fertility intentions. Our analysis provided no support for this alternative explanation, and, indeed, those with higher distress scores were significantly less likely to relinquish fertility intentions. These findings support Wethington et al.'s (1997), who found no evidence that distress predicts changed life trajectories.

Fixed effects pooled time series analysis showed that relinquished fertility intentions were significantly associated with increased distress levels. This main effect was conditioned by three interaction effects showing that relinquishing fertility intentions was more distressing for women, for those with declining health, and for those with higher education. For women, this effect is equivalent to an increment in depressive symptoms of one third of a standard deviation. This is consistent with McMahon's (1995) argument that the symbolic importance of parenting is particularly important for women. Among those whose health remains excellent, there appears to be no penalty for relinquishing fertility intentions. Possibly those without health barriers more or less willingly relinquish their fertility aspirations in favor of alternative goals, whereas those in declining health give up their intentions less willingly. In the latter case, fertility intentions may be one among many goals that individuals have had to scale back on or relinquish in the face of declining health. The negative effect of no longer intending was greater for those with higher education. To the extent that longer education is associated with a planned postponement of fertility and perhaps bypassing previous opportunities to have children, we speculate that subsequent recognition that the opportunity has passed might be associated with greater feelings of personal responsibility and distress (Hewlett, 2002).

Focusing on a smaller sample of individuals in the same unions at Time 1 and 2, we found that the effects of no longer intending depended on changes in relationship quality. When relationship quality declined, relinquished fertility was associated with increased depressive symptoms. When relationships were improving, however, the effect of relinquished intentions decreased incrementally so that it was virtually nil when relationship quality was high.

The most surprising of our findings was absence of support for our expectation that the effect of relinquishing fertility intentions would be most distressing for those with no children at Time 1. Extensive analysis showed that the effect did not depend significantly on initial parity. This finding suggests that the issue may have less to do with parenthood status and more to do with sexual identity or sense of reproductive potential. Although not as final as the end of fecundity marked by sterilization or menopause, deciding that you will give up a strong intention to have more children closes a door that had been left open. As previous work on the end of fecundity (e.g., Groat et al., 1990; Hillis et al., 1999) suggests, closing that door may provoke regret. In our analysis, this seems most likely to be true for women than men, regardless of parity. In the words of one of Hewlett's (2002) respondents, not having a wanted second child can result in an "aching loss around children we will never have" (p. 99).

These analyses are only a partial approach to examining the social-psychological consequences of relinquishing intentions to have a child. Our data do not allow us to assess why individuals who initially intended (additional) children no longer do. There is undoubtedly a continuum of voluntariness here, where some are held back by circumstantial barriers such as failure to marry a partner who wants children, some by the demands of their job or their current children, some by biomedical problems, and yet others by changed life trajectories. On one hand, the fact that relinquishing intended fertility is more distressing among those with declining health suggests that biomedical barriers to fertility may be more distressing than other kinds of barriers. This supports McQuillan et al.'s (2003) finding that childlessness in the presence of biomedical infertility but not general childlessness has long-term consequences for distress for women. On the other hand, biomedical infertility does not generally result in poor general health. Many social and health conditions make pregnancy unwise or impossible for the mother but are rarely discussed in infertility research or treatment (for an exception, see Jacob, McQuillan, Greil, \& White, 2003). For example, back problems, diabetes, multiple sclerosis, cancer, high blood pressure, and asthma can end plans for pregnancy and other 
life goals. Thus, our findings suggest that research on infertility-related distress should be extended beyond a focus on specific forms of subfecundity to include broader health measures.

In conclusion, our research supports an argument that fertility potential is important to many people's psychosocial well-being and that people who give up a strong intention to have a child and close the door on future fertility, especially women, those in worsening health, and the better educated, increase their distress levels over time. Partnered individuals show more depressive symptoms when relinquished fertility intentions occur in the context of declining relationship quality. Although we cannot demonstrate conclusive causal order, we believe these results provide an argument for broadening social science research on fertility and infertility. Those who study fertility intentions generally focus on predictive capacity of such intentions without considering the consequences to the men and women who do not meet their intentions. Similarly, those who study biomedical infertility too often focus only on those with specific forms of subfecundity (and often on a subset of these who seek treatment). The analysis presented here suggests that relinquishing fertility intentions, regardless of the reasons, is consequential enough to be worth examining.

\section{Note}

We wish to thank David Johnson of Pennsylvania State University for providing helpful comments on an earlier draft of this paper. This paper was presented at the 2002 meetings of the Midwest Sociological Society in Milwaukee, Wisconsin.

\section{References}

Abma, J., Chandra, A., Mosher, W., Peterson, L., \& Piccinino, L. (1997). Fertility, family planning, and women's health: New data from the $1995 \mathrm{Na}$ tional Survey of Family Growth. National Center for Health Statistics. Vital and Health Statistics, 23 (19), 1-125.

Allison, P. D. (1994). Using panel data to estimate the effects of events. Sociological Methods and Research, 23, 174-199.

Andrews, F. M., Abbey, A., \& Halman, L. J. (1991). Stress from infertility, marriage factors, and subjective well-being of wives and husbands. Journal of Health and Social Behavior, 32, 238-253.
Aneshensel, C. S. (1992). Social stress: Theory and research. Annual Review of Sociology, 18, 15-38.

Beets, G. C. N., Liefbroer, A. C., \& Gierveld, J. (1999). Changes in fertility values and behaviour: A life course perspective. In R. Lee (Ed.), Dynamics of values in fertility change (pp. 100-120). Oxford: Oxford UP.

Bulcroft, R., \& Teachman, J. (2004). Ambiguous constructions: Development of a childless or childfree life course. In M. C. Coleman \& L. H. Ganong (Eds.), Handbook of contemporary families (pp. 116224). Newbury Park, CA: Sage.

Connidis, I. A., \& McMullin, J. A. (1993). To have or have not: Parent status and the subjective wellbeing of older man and women. Gerontologist, 33, 630-367.

Elson, J. (2004). Am I still a woman? Hysterectomy and gender identity. Philadelphia: Temple UP.

Greil, A. L. (1991). Not yet pregnant: Infertile couples in contemporary America. New Brunswick, NJ: Rutgers UP.

Groat, H. T., Neal, A. G., \& Wicks, J. W. (1990). Sterilizlation anxiety and fertility control in later years of childbearing. Journal of Marriage and the Family, 52, 249-258.

Hagewen, K. J., \& Morgan, S. P. (2005). Intended and ideal family size in the United States, 1970-2002. Population and Development Review, 31, 507-527.

Hays, S. (1996). The cultural contradictions of motherhood. New Haven, CT: Yale UP.

Heaton, T. B., Jacobson, C. K., \& Holland, K. (1999). Persistence and change in decisions to remain childless. Journal of Marriage and the Family, 61, 531-539.

Hewlett, S. A. (2002). Creating a life: Professional women and the quest for children. New York: Talk Miramax Books.

Hill, M. (1997). SPSS missing value analysis 7.5. Chicago: SPSS.

Hillis, S. D., Marchbanks, P. A., Tylor, L. R., \& Peterson, H. B. (1999). Poststerilization regret: Findings from the United States collaborative review of sterilization. Obstetrics and Gynecology, 96, 889-895.

Jacob, M. C., McQuillan, J., Greil, A. L., \& White, L. (2003). Psychological distress by type of fertility problem [Abstract]. In Program Supplement, 59th Annual Meeting of the American Society for Reproductive Medicine (p. S51), San Antonio, TX. 
Johnson, D. R. (2005). Two-wave panel analysis: Comparing statistical methods for the study of the effects of transitions. Journal of Marriage and Family, 67, 1061-1075.

King, R. B. (2003). Subfecundity and anxiety in a nationally representative sample. Social Science $\mathcal{E}$ Medicine, 56, 739-751.

Koropeckyj-Cox, T. (1988). Loneliness and depression in middle and old age: Are the childless more vulnerable? Journals of Gerontology Series B, 53B, S303-S312.

McMahon, M. (1995). Engendering motherhood: Identity and self-transformation in women's lives. New York: Guilford Press.

McQuillan, J., Greil, A. L., White, L., \& Jacob, M. C. (2003). Frustrated fertility: Infertility and psychological distress among women. Journal of Marriage and Family, 65, 1007-1019.

Miller, K. (2004). Assisted reproduction may change birth intentions. Fertility and Sterility, 81, 572-581.

Miller, W. B., \& Pasta, D. J. (1995). Behavioral intentions: Which ones predict fertility behavior in married couples? Journal of Applied Social Psychology, 25, 530-556.

Mirowsky, J., \& Ross, C. E. (1992). Age and depression. Journal of Health and Social Behavior, 33, 187-205.

Morgan, S. P. (1982). Parity-specific fertility intentions and uncertainty: The United States, 1970 to 1976. Demography, 19, 315-34.

Morgan, S. P. (2003). Is low fertility a twenty-first century demographic crisis. Demography, 40, 589-604.

Nock, S. L. (1987). The symbolic meaning of childbearing. Journal of Family Issues, 8, 373-393.

Patterson, G. C., Coffey, C., Posterino, M., Carlin, J. B., \& Bowes, G. (2003). Life events and early onset depression: Cause or consequence? Psychological Medicine, 33, 1203-1210.

Pearlin, L., Lieberman, M. A., Menaghan, E. G., \& Mullan, J. T. (1981). The stress process. Journal of Health and Social Behavior, 22, 337-356.

Quesnel-Vallee, A., \& Morgan, S. P. (2004). Missing the target: Correspondence of fertility intentions and behavior in the U.S. Population Research and Policy Review, 22, 497-525.

Radloff, L. (1977). The CES-D scale: A self -report depression scale for research in the general population. Applied Psychological Measurement, 1, 385-401.
Roeske, N. (1978). Quality of life factors affecting the response to hysterectomy. Journal of Family Practice, 7, 483-488.

Ross, C. E., \& Sastry, J. (1999). The sense of personal control: Social-structural causes and emotional consequences. In C. S. Aneshensel \& J. C. Phelan (Eds.), Handbook of the sociology of mental health (pp. 369-394). New York: Plenum.

Schoen, R., Astone, N. M., Kim, Y. J., Nathanson, C. A., \& Fields, J. M. (1999). Do fertility intentions affect fertility behavior? Journal of Marriage and the Family, 61, 790-799.

Sweet, J., \& Bumpass, L. (1996). The National Survey of Families and Households-Waves 1 and 2: Data description and documentation. Madison: Center for Demography and Ecology, University of Wisconsin-Madison.

Sweet, J., Bumpass, L., \& Call, V. (1988). The design and content of The National Survey of Families and Households. Madison: Center for Demography and Ecology, University of Wisconsin-Madison.

Thoits, P. A. (1994). Stressors and problem-solving: The individual as psychological activist. Journal of Health and Social Behavior, 35, 143-60.

Thoits, P. A. (1999). Self, identity, stress, and mental health. In C. S. Aneshensel \& J. C. Phelan (Eds.), Handbook of the sociology of mental health (pp. 345368). New York: Kluwer.

Thomson, E. (1997). Couple childbearing desires, intentions, and births. Demography, 34, 343-354.

Thornton, A., \& Young-DeMarco, L. (2001). Four decades of trends in attitudes toward family issues in the United States: The 1960s through the 1990s. Journal of Marriage and the Family, 63, 1009-1038.

Umberson, D., \& Gove, W. R. (1989). Parenthood and psychological well-being: Theory, measurement, and stage in the family life course. Journal of Family Issues, 40, 440-462.

Westoff, C. F., \& Ryder, N. B. (1977) The predictive validity of reproductive intentions. Demography, 14, 431-453.

Wethington, E., Cooper, H., \& Holmes, C. S. (1997). Turning points in midlife. In I. Gotlib \& B. Wheaton (Eds.), Stress and adversity over the life course: Trajectories and turning-points (pp. 215-231). New York: Cambridge.

Zhang, A., \& Hayward, M. D. (2001). Childlessness and the psychological well-being of older persons. Journals of Gerontology: Social Sciences, 56, S311-S320. 